\title{
Prevalence of Overweight and Obesity in Italy (2001-2008): Is There a Rising Obesity Epidemic?
}

\author{
ROCCO MICCIOLO, MD, VINCENZO DI FRANCESCO, MD, FRANCESCO FANTIN, MD, \\ LUISA CANAL, PHD, TAMARA B. HARRIS, MD, OTTAVIO BOSELLO, MD, AND \\ MAURO ZAMBONI, MD
}

\begin{abstract}
PURPOSE: To provide national, population-based estimates of the prevalence of overweight and obesity in the Italian population.

METHODS: Prevalence estimates of overweight and obesity were calculated in seven waves (2001-2008) of the cross-sectional Multipurpose Household Survey organized by the Italian National Institute of Statistics, which are representative of the general adult Italian population. Sampling weights were used to estimate prevalence figures as well as their standard errors. Mean-difference plot was used to evaluate changes in the distribution of body mass index across sex and age categories.

RESULTS: Almost half of Italian men and about 1 of 3 Italian women are overweight or obese. Between 2001 and 2008 the age-standardized prevalence of overweight (obesity) increased $1.4 \%(1.9 \%)$ in men and $0.4 \%(0.5 \%)$ in women. Mean-difference plots showed an upward shift for body mass index distribution with an increasing skewness.

CONCLUSIONS: The obesity epidemic is one of the major issues in United States and other developed countries. However, if for "epidemic" we mean that in Italy obesity is steadily increasing, then our data give little support to this interpretation. In fact, trends observed between 1983 and 2008 suggest that the rates of changes in the prevalence of overweight and/or obesity are not increasing.

Ann Epidemiol 2010;20:258-264. (c) 2010 Elsevier Inc. All rights reserved.
\end{abstract}

KEY wORDS: Body Mass Index, Obesity, Overweight, Prevalence.

\section{INTRODUCTION}

Overweight and obesity are well-known causes of morbidity and mortality $(1,2)$ and may lessen life expectancy, especially in younger people (3). Between 1980 and 2002 the prevalence of overweight and obesity increased in the United States in subjects aged 20 years and older $(4,5)$. More recently, data from the National Health and Nutrition Examination Survey conducted in 2003 2004 showed that the prevalence of overweight among children and adolescents and that of obesity in men have continued to increase significantly, whereas the prevalence of obesity among women leveled off (6). In

From the Department of Sociology and Social Research, University of Trento, Trento, Italy (R.M.); Department of Medical and Surgical Science, Geriatric Medicine, University of Verona, Verona, Italy (V.D.F., F.F., O.B., M.Z.); Department of Cognitive and Education Sciences, University of Trento, Trento, Italy (L.C.); and Office of Geriatric Epidemiology Demography and Biometry Program, National Institute of Aging, Bethesda, MD (T.B.H.).

Address correspondence to: Rocco Micciolo, Department of Sociology and Social Research, University of Trento, Via Verdi, 26, 38122 Trento, Italy. Tel. : +39 461 282913; Fax: +39 461 281348. E-mail: rocco.micciolo@unitn.it.

Received August 18, 2009; accepted January 3, 2010. recent years, the prevalence of overweight and obesity has increased in almost all developed countries (7). However, the prevalence of obesity seems to be lower in European Countries than in the United States, and more importantly the rates of changes seem to show little or no increase in Europe $(7,8)$. The aim of the present study is to provide national, population-based estimates of the prevalence of overweight and obesity with the use of data from seven Italian National Surveys conducted between 2001 and 2008 .

\section{MATERIALS AND METHODS}

Prevalence estimates of overweight and obesity were calculated with the use of data from the Multipurpose Household Survey (MHS), an integrated system of crosssectional social surveys conducted by the Italian National Institute of Statistics, which aimed to collect information about health and lifestyle habits from a representative sample of the adult civilian, noninstitutionalized Italian population. For each survey an independent sample was selected, and final sample units (households) were drawn by the use of a two-stage stratified sample design $(9,10)$. Strata were represented by geographical areas (Italian 


\begin{tabular}{l} 
Selected Abbreviations and Acronyms \\
MHS = Multipurpose Household Survey \\
BMI = body mass index \\
\hline
\end{tabular}

regions) and municipalities. The latter were sampled according to a "probability proportional to size" sample design, where the size variable was the number of inhabitants of the municipalities. All the individuals of the selected households were interviewed. All interviews were conducted face-to-face by civil servants in the houses of the families selected. Nonresponse rate accounted for $17 \%$ of the total sample size. It was mostly attributable to refusal (approximately $9 \%$ of the total sample size), whereas the list error had a percentage of $5 \%$ and nonresponse as the result of other reasons counted for $3 \%$ of the sampled households (10). The present report is based on data from the last seven MHS waves: 287,336 subjects aged 20 to 99 years $(137,234$ men, 150,102 women).

From the MHS questionnaire, information on sex and age was obtained. The questionnaire included (for every household member aged 20 and older) self-reported anthropometric data such as height and weight. Body mass index (BMI) was calculated as weight in kilograms divided by the square of height in meters. Participants were classified as overweight if their BMI was between 25.0 and $29.9 \mathrm{~kg} /$ $\mathrm{m}^{2}$ and as obese if their BMI was $30.0 \mathrm{~kg} / \mathrm{m}^{2}$ or greater. These definitions are consistent with those of the World Health Organization.

For all surveys, sampling weights were made available by the Italian National Institute of Statistics to take into account the different probabilities of selection resulting from the sample design. These were always considered when calculating prevalence figures. Given the complex sampling design, the Taylor series linearization method was adopted to obtain correct estimates of variance (11). Prevalence figures were directly standardized to the general age structure of the overall data set. Trends across age groups and survey years were evaluated by means of weighted regression analysis that used as weights the reciprocal of the variances of the prevalence figures. Linear, quadratic, and cubic terms were considered both for age groups and for survey years as well as their interactions. A significance level of 0.05 was always adopted.

To evaluate changes in the distribution of BMI across sex and age categories the Tukey mean-difference plot was employed (12). This is a graphical method for comparing distributions that investigates shifts by comparing corresponding quantiles. The points on the plot represent the differences between two distributions at a given quantile level against the means of the same quantile level from the two distributions. If the two distributions are the same, the quantiles would be equal and the differences would all be zero. The location of the points on the $y$-axis shows the direction and the magnitude of any shift between the distributions. The shape of the line formed by the points suggests the nature of the shift. Weighted percentiles were calculated using the sampling weights. Statistical analyses were performed with $\mathrm{R}$ for Windows (13).

\section{RESULTS}

Tables 1 and 2 show, for men and women, respectively, both the age-specific and the age-standardized prevalence of overweight and of obesity in Italy for each of the seven surveys. In men, the age-standardized prevalence of overweight (obesity) shows an increase of 1.4\% (1.9\%) between 2001 and 2008 (Table 1). In women, overweight prevalence increased $0.4 \%$ and obesity $0.5 \%$ (Table 2 ).

Age-specific prevalences reported in Tables 1 and 2 suggest that trends may potentially differ by sex, age group, and overweight outcome. To assess whether temporal trends are statistically significant and/or whether they differ across demographic groups, four separate regression analyses (according to sex and overweight outcome) were performed.

As expected, age always showed the most significant effects. In all the analyses the regression coefficients for the linear, the quadratic, and the cubic terms were highly significant (with $p$ values always below $10^{-6}$ ). The quadratic term modeled the pattern of the prevalence of overweight outcome (always lower at extreme age groups), whereas the cubic term allowed for asymmetry in the pattern. In all the analyses the linear trend for survey year was significant $(p<.01)$ but not the quadratic or the cubic terms ( $p$ values ranging between .209 and .571 ), nor their interactions with age ( $p$ values ranging between .178 and .929). In addition, when considering the prevalence of overweight, a significant interaction between survey year and the quadratic term of age was found ( $p=.045$ in men and $p=.008$ in women).

According to the coefficients of the pertinent model (not shown), the estimated yearly increase in the prevalence of obesity was $0.28 \%$ in men and $0.14 \%$ in women. However, trends for prevalence of overweight were age dependent. Both in men and in women the predicted yearly increase was more pronounced after 60 years; at 70 years, it was $0.38 \%$ in men and $0.12 \%$ in women.

Figure 1 shows the mean-difference plots comparing the distribution of BMI in 2007 and 2008 MHSs with that of 2001 and 2002. Each point on the plot represents 
TABLE 1. Prevalence estimates (\%) of overweight and obesity in Italian adult men by age and survey year from Multipurpose Household Surveys

\begin{tabular}{|c|c|c|c|c|c|c|c|c|}
\hline \multirow{3}{*}{$\frac{\text { Age, years }}{20-29}$} & \multirow{3}{*}{$\begin{array}{l}\text { Survey year } \\
2001\end{array}$} & \multirow{3}{*}{$\frac{\mathrm{n}}{3401}$} & \multicolumn{3}{|c|}{ Overweight } & \multicolumn{3}{|c|}{ Obese } \\
\hline & & & \multirow{2}{*}{$\frac{\text { Prevalence }}{23.9}$} & \multicolumn{2}{|c|}{$95 \% \mathrm{CI}$} & \multirow{2}{*}{$\frac{\text { Prevalence }}{2.5}$} & \multicolumn{2}{|c|}{$95 \% \mathrm{CI}$} \\
\hline & & & & 21.9 & 25.8 & & 1.8 & 3.3 \\
\hline & 2002 & 3565 & 24.3 & 22.5 & 26.2 & 2.3 & 1.6 & 3.0 \\
\hline & 2003 & 3385 & 22.5 & 20.6 & 24.3 & 2.6 & 1.9 & 3.4 \\
\hline & 2005 & 2944 & 24.5 & 22.4 & 26.7 & 3.5 & 2.6 & 4.4 \\
\hline & 2006 & 2745 & 22.5 & 20.4 & 24.5 & 3.7 & 2.7 & 4.6 \\
\hline & 2007 & 2661 & 24.0 & 21.9 & 26.1 & 3.5 & 2.5 & 4.4 \\
\hline & 2008 & 2621 & 26.9 & 24.7 & 29.1 & 3.8 & 2.8 & 4.7 \\
\hline \multirow[t]{7}{*}{$30-39$} & 2001 & 4123 & 38.2 & 36.2 & 40.2 & 6.4 & 5.5 & 7.4 \\
\hline & 2002 & 4193 & 38.6 & 36.7 & 40.6 & 5.1 & 4.2 & 5.9 \\
\hline & 2003 & 4102 & 36.7 & 34.8 & 38.7 & 6.0 & 5.1 & 6.9 \\
\hline & 2005 & 3700 & 38.6 & 36.5 & 40.8 & 7.2 & 6.1 & 8.3 \\
\hline & 2006 & 3639 & 39.9 & 37.7 & 42.1 & 6.4 & 5.4 & 7.4 \\
\hline & 2007 & 3447 & 40.0 & 37.8 & 42.2 & 7.3 & 6.2 & 8.4 \\
\hline & 2008 & 3457 & 40.1 & 37.9 & 42.2 & 7.8 & 6.7 & 8.9 \\
\hline \multirow[t]{7}{*}{$40-49$} & 2001 & 3764 & 48.6 & 46.2 & 51.0 & 9.7 & 8.5 & 11.0 \\
\hline & 2002 & 3917 & 45.2 & 43.0 & 47.5 & 10.8 & 9.6 & 12.1 \\
\hline & 2003 & 3842 & 48.0 & 45.7 & 50.4 & 10.0 & 8.8 & 11.2 \\
\hline & 2005 & 3647 & 48.3 & 45.8 & 50.8 & 10.0 & 8.7 & 11.3 \\
\hline & 2006 & 3692 & 48.6 & 46.2 & 51.0 & 11.3 & 10.0 & 12.6 \\
\hline & 2007 & 3740 & 47.1 & 44.8 & 49.5 & 11.7 & 10.4 & 13.0 \\
\hline & 2008 & 3796 & 47.5 & 45.2 & 49.8 & 10.3 & 9.1 & 11.5 \\
\hline \multirow[t]{7}{*}{ 50-59 } & 2001 & 3353 & 50.8 & 48.2 & 53.5 & 12.5 & 11.0 & 14.0 \\
\hline & 2002 & 3581 & 51.8 & 49.2 & 54.4 & 12.8 & 11.3 & 14.3 \\
\hline & 2003 & 3597 & 51.0 & 48.3 & 53.6 & 13.3 & 11.8 & 14.8 \\
\hline & 2005 & 3248 & 54.7 & 51.8 & 57.6 & 14.4 & 12.8 & 16.1 \\
\hline & 2006 & 3192 & 51.2 & 48.4 & 54.0 & 14.9 & 13.2 & 16.5 \\
\hline & 2007 & 3124 & 52.4 & 49.6 & 55.2 & 14.9 & 13.3 & 16.6 \\
\hline & 2008 & 3092 & 51.7 & 48.9 & 54.4 & 15.2 & 13.6 & 16.8 \\
\hline \multirow[t]{7}{*}{$60-69$} & 2001 & 2813 & 52.0 & 49.0 & 55.1 & 12.7 & 11.0 & 14.4 \\
\hline & 2002 & 3155 & 51.3 & 48.6 & 54.1 & 13.7 & 12.1 & 15.3 \\
\hline & 2003 & 2936 & 52.8 & 49.8 & 55.7 & 14.5 & 12.8 & 16.2 \\
\hline & 2005 & 2688 & 52.4 & 49.3 & 55.5 & 15.3 & 13.4 & 17.1 \\
\hline & 2006 & 2731 & 51.8 & 48.7 & 54.9 & 15.4 & 13.6 & 17.2 \\
\hline & 2007 & 2817 & 52.7 & 49.7 & 55.7 & 16.0 & 14.2 & 17.8 \\
\hline & 2008 & 2797 & 52.7 & 49.8 & 55.7 & 15.3 & 13.5 & 17.0 \\
\hline \multirow[t]{7}{*}{ 70-99 } & 2001 & 2743 & 46.9 & 44.0 & 49.8 & 10.1 & 8.6 & 11.7 \\
\hline & 2002 & 2843 & 46.5 & 43.7 & 49.3 & 10.3 & 8.8 & 11.8 \\
\hline & 2003 & 2764 & 45.7 & 42.9 & 48.6 & 12.5 & 10.8 & 14.1 \\
\hline & 2005 & 2614 & 46.5 & 43.5 & 49.4 & 12.6 & 10.9 & 14.3 \\
\hline & 2006 & 2877 & 48.9 & 46.0 & 51.8 & 12.7 & 11.1 & 14.4 \\
\hline & 2007 & 2909 & 50.5 & 47.5 & 53.4 & 11.2 & 9.6 & 12.7 \\
\hline & 2008 & 2979 & 50.5 & 47.7 & 53.4 & 13.4 & 11.8 & 15.0 \\
\hline \multirow[t]{7}{*}{ 20-99 } & 2001 & 20197 & 43.2 & 42.2 & 44.2 & 8.8 & 8.3 & 9.4 \\
\hline & 2002 & 21254 & 42.7 & 41.7 & 43.7 & 8.9 & 8.4 & 9.4 \\
\hline & 2003 & 20626 & 42.5 & 41.5 & 43.5 & 9.5 & 9.0 & 10.0 \\
\hline & 2005 & 18841 & 43.9 & 42.9 & 45.0 & 10.2 & 9.6 & 10.8 \\
\hline & 2006 & 18876 & 43.6 & 42.6 & 44.7 & 10.4 & 9.9 & 11.0 \\
\hline & 2007 & 18698 & 44.1 & 43.1 & 45.2 & 10.6 & 10.0 & 11.1 \\
\hline & 2008 & 18742 & 44.6 & 43.5 & 45.6 & 10.7 & 10.1 & 11.2 \\
\hline
\end{tabular}

Prevalences for 20- to 99-year age group were directly standardized to the general age structure of the overall data set. Figures were calculated taking into account the probabilities of selection resulting from the survey sample design.

$95 \% \mathrm{CI}=95 \%$ confidence intervals.

the mean (on the $x$-axis) and the difference (on the $y$ axis) for an even percentile (from the 2 nd up to the 98th). The details differ between sex-age groups. In men the 2007 and 2008 distribution appears generally shifted upward; moreover, the difference between percentiles appears greater in the upper portion of the distribution, 
TABLE 2. Prevalence estimates (\%) of overweight and obesity in Italian adult women by age and survey year from Multipurpose Household Surveys

\begin{tabular}{|c|c|c|c|c|c|c|c|c|}
\hline \multirow{3}{*}{$\frac{\text { Age, years }}{20-29}$} & \multirow{3}{*}{$\frac{\text { Survey year }}{2001}$} & \multirow{3}{*}{$\frac{\mathrm{n}}{3456}$} & \multicolumn{3}{|c|}{ Overweight } & \multicolumn{3}{|c|}{ Obese } \\
\hline & & & \multirow{2}{*}{$\frac{\text { Prevalence }}{8.0}$} & \multicolumn{2}{|c|}{$95 \% \mathrm{CI}$} & \multirow{2}{*}{$\frac{\text { Prevalence }}{1.5}$} & \multicolumn{2}{|c|}{$95 \%$ CI } \\
\hline & & & & 6.7 & 9.2 & & 0.9 & 2.1 \\
\hline & 2002 & 3529 & 8.1 & 6.9 & 9.3 & 1.4 & 0.9 & 2.0 \\
\hline & 2003 & 3398 & 8.3 & 7.1 & 9.5 & 1.4 & 0.8 & 1.9 \\
\hline & 2005 & 2970 & 9.3 & 7.9 & 10.8 & 1.3 & 0.7 & 2.0 \\
\hline & 2006 & 2770 & 9.2 & 7.7 & 10.6 & 2.1 & 1.3 & 2.8 \\
\hline & 2007 & 2591 & 10.2 & 8.7 & 11.8 & 2.5 & 1.6 & 3.3 \\
\hline & 2008 & 2529 & 10.8 & 9.3 & 12.4 & 2.3 & 1.5 & 3.1 \\
\hline \multirow[t]{7}{*}{ 30-39 } & 2001 & 4297 & 14.1 & 12.8 & 15.5 & 3.1 & 2.4 & 3.8 \\
\hline & 2002 & 4354 & 13.2 & 12.0 & 14.5 & 3.4 & 2.7 & 4.1 \\
\hline & 2003 & 4104 & 15.4 & 14.1 & 16.8 & 3.5 & 2.8 & 4.3 \\
\hline & 2005 & 3838 & 15.5 & 14.0 & 16.9 & 4.0 & 3.1 & 4.8 \\
\hline & 2006 & 3696 & 16.5 & 15.0 & 18.0 & 4.4 & 3.5 & 5.3 \\
\hline & 2007 & 3613 & 16.4 & 14.9 & 17.9 & 4.4 & 3.6 & 5.3 \\
\hline & 2008 & 3665 & 15.2 & 13.8 & 16.7 & 4.1 & 3.3 & 5.0 \\
\hline \multirow[t]{7}{*}{ 40-49 } & 2001 & 3926 & 22.6 & 20.8 & 24.4 & 6.8 & 5.7 & 7.9 \\
\hline & 2002 & 4064 & 22.1 & 20.4 & 23.8 & 6.4 & 5.4 & 7.4 \\
\hline & 2003 & 4118 & 21.0 & 19.3 & 22.6 & 7.4 & 6.3 & 8.4 \\
\hline & 2005 & 3840 & 22.8 & 21.0 & 24.6 & 8.5 & 7.3 & 9.7 \\
\hline & 2006 & 3783 & 21.1 & 19.4 & 22.8 & 7.7 & 6.6 & 8.8 \\
\hline & 2007 & 3774 & 21.7 & 20.0 & 23.4 & 8.0 & 6.9 & 9.1 \\
\hline & 2008 & 3930 & 21.2 & 19.6 & 22.9 & 6.9 & 5.9 & 8.0 \\
\hline \multirow[t]{7}{*}{ 50-59 } & 2001 & 3480 & 33.2 & 30.9 & 35.4 & 13.8 & 12.3 & 15.4 \\
\hline & 2002 & 3687 & 31.6 & 29.6 & 33.7 & 13.0 & 11.6 & 14.4 \\
\hline & 2003 & 3635 & 31.2 & 29.1 & 33.3 & 13.8 & 12.3 & 15.2 \\
\hline & 2005 & 3318 & 30.8 & 28.6 & 33.0 & 14.6 & 13.0 & 16.3 \\
\hline & 2006 & 3386 & 31.5 & 29.3 & 33.6 & 15.4 & 13.8 & 17.0 \\
\hline & 2007 & 3306 & 32.1 & 29.9 & 34.3 & 12.7 & 11.2 & 14.2 \\
\hline & 2008 & 3311 & 31.4 & 29.3 & 33.6 & 12.5 & 11.1 & 14.0 \\
\hline \multirow[t]{7}{*}{$60-69$} & 2001 & 3167 & 39.6 & 37.1 & 42.1 & 14.8 & 13.1 & 16.4 \\
\hline & 2002 & 3283 & 37.7 & 35.3 & 40.0 & 13.9 & 12.3 & 15.5 \\
\hline & 2003 & 3148 & 35.5 & 33.1 & 37.9 & 16.2 & 14.5 & 17.9 \\
\hline & 2005 & 2871 & 35.0 & 32.5 & 37.4 & 18.0 & 16.2 & 19.9 \\
\hline & 2006 & 2920 & 36.0 & 33.4 & 38.5 & 18.3 & 16.4 & 20.2 \\
\hline & 2007 & 2961 & 38.2 & 35.7 & 40.6 & 14.2 & 12.5 & 15.8 \\
\hline & 2008 & 3002 & 37.0 & 34.5 & 39.4 & 14.8 & 13.1 & 16.4 \\
\hline \multirow[t]{7}{*}{ 70-99 } & 2001 & 3886 & 33.9 & 31.9 & 35.9 & 11.9 & 10.6 & 13.2 \\
\hline & 2002 & 4218 & 35.1 & 33.2 & 37.1 & 13.1 & 11.8 & 14.3 \\
\hline & 2003 & 4138 & 36.5 & 34.5 & 38.5 & 12.2 & 10.9 & 13.5 \\
\hline & 2005 & 3807 & 36.5 & 34.4 & 38.7 & 12.9 & 11.5 & 14.2 \\
\hline & 2006 & 4126 & 36.7 & 34.6 & 38.8 & 12.8 & 11.4 & 14.1 \\
\hline & 2007 & 4055 & 39.1 & 37.0 & 41.2 & 13.4 & 12.1 & 14.8 \\
\hline & 2008 & 4152 & 37.4 & 35.4 & 39.4 & 13.6 & 12.3 & 14.9 \\
\hline \multirow[t]{7}{*}{ 20-99 } & 2001 & 22212 & 25.1 & 24.4 & 25.9 & 8.5 & 8.0 & 9.0 \\
\hline & 2002 & 23135 & 24.6 & 23.9 & 25.4 & 8.5 & 8.0 & 9.0 \\
\hline & 2003 & 22541 & 24.7 & 24.0 & 25.5 & 9.0 & 8.5 & 9.4 \\
\hline & 2005 & 20644 & 25.1 & 24.3 & 25.9 & 9.8 & 9.2 & 10.3 \\
\hline & 2006 & 20681 & 25.3 & 24.5 & 26.0 & 10.0 & 9.4 & 10.5 \\
\hline & 2007 & 20300 & 26.4 & 25.6 & 27.2 & 9.2 & 8.7 & 9.7 \\
\hline & 2008 & 20589 & 25.5 & 24.8 & 26.3 & 9.0 & 8.5 & 9.5 \\
\hline
\end{tabular}

Prevalences for 20- to 99-years age group were directly standardized to the general age structure of the overall data set. Figures were calculated taking into account the probabilities of selection resulting from the survey sample design.

showing an increased skewness. For women the pattern is different. For the age range 50 to 69 years, the difference between the percentiles is close to zero. An increased skewness is evident between 20 and 39 years. An upward shift appears for women older than 69 years. Although the magnitude of the differences varies from group to group, 

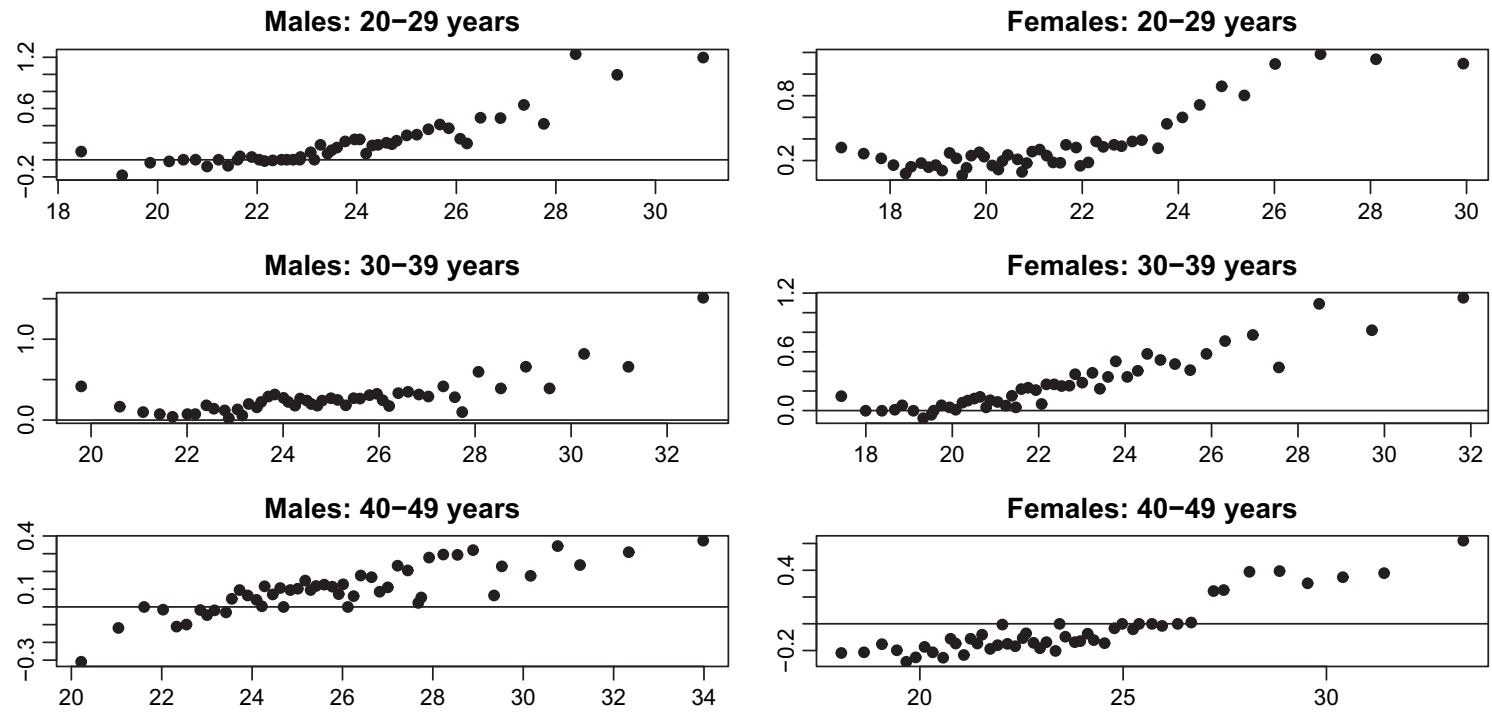

Females: $40-49$ years

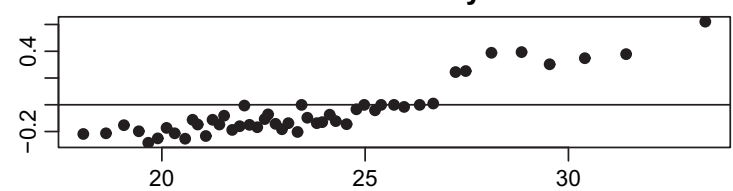

Males: $50-59$ years
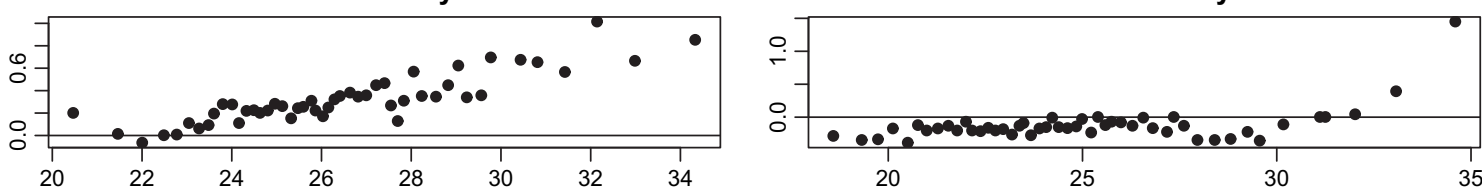

Males: $60-69$ years

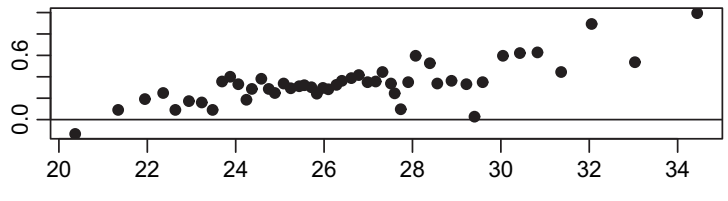

60-69 years

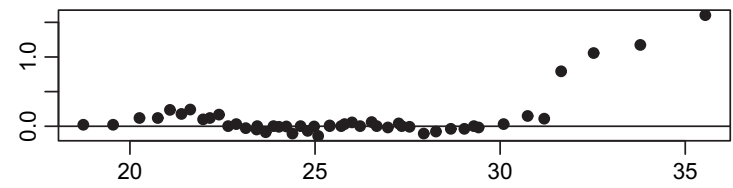

Males: $70-99$ years

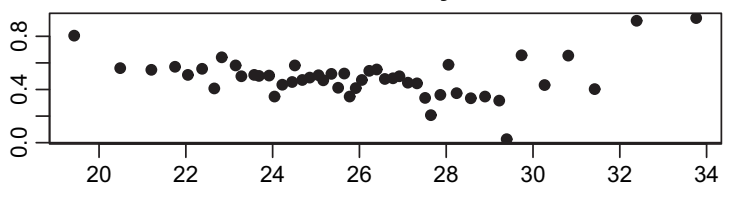

Females: $70-99$ years

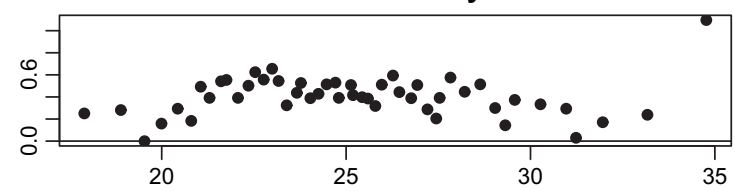

FIGURE 1. Mean-difference plots for the distribution of body mass index from 2001-2002 and from 2007-2008 Italian Multipurpose Household Surveys for adults aged 20-99 years, by sex and age group.

the largest differences are generally below 1 BMI unit and are observed at the highest percentiles of the distribution.

\section{DISCUSSION}

The present study provides the most recent prevalence estimates of overweight and obesity in Italy. Overweight is much more common in adult men than in adult women, as well as obesity, even if at a lesser degree. In the 7-year period considered, overweight (obesity) increased $1.4 \%$ $(1.9 \%)$ in men and $0.4 \%(0.5 \%)$ in women. Similar analyses were performed in Italy with the use of data from the Italian National Health Surveys (14, 15). Between 1983 and 1994, the proportion of overweight subjects increased from $34.1 \%$ to $39.6 \%$ in men and from $21.3 \%$ to $25.0 \%$ in women, whereas a moderate decrease both in men (from $7.1 \%$ to $6.5 \%$ ) and in women (from $7.6 \%$ to $6.3 \%$ ) was observed for obesity (14). In the 2000 survey the prevalence of overweight (obesity) was $40.6 \%$ (8.3\%) in men and $24.6 \%(8.1 \%)$ in women (15). Therefore during a 25-year period (from 1983 to 2008) the prevalence of overweight increased $10.5 \%$ in men $(0.42 \% /$ year) and $4.2 \%$ in women $(0.168 \% /$ year $)$; the prevalence of obesity increased $3.6 \%$ in men $(0.144 \% /$ year $)$ and $1.4 \%$ in women (0.056\%/year).

Although these findings, based on large samples representative of the general adult Italian population, show that overweight and obesity are a major health issue in Italy, 
the prevalence of both overweight and obesity appears still much lower in Italy than in the United States $(4,5)$. In fact the most recent prevalence estimates of overweight and obesity in the United States show that more than $60 \%$ of men and women are overweight or obese, and of these, more than $30 \%$ are obese (6). More importantly, a significant increasing trend in the prevalence of overweight and obesity was reported $(5,6)$, suggesting an even greater epidemic of obesity.

We also investigated changes in the distribution of BMI showing qualitative differences broadly similar to those found in United States by Flegal and Troiano (16). However, quantitatively, these authors found approximately 3 to 4 BMI units' differences, whereas in the present study they were generally below 1 BMI unit.

Several reasons may explain differences in overweight outcome between Italy and the United States. It is possible that some factors are affecting the entire distribution of BMI and that the search for causes will need to consider the broader socioenvironmental context. Factors such as diet, food composition, food availability, portion sizes, fast food consumption, increasingly sedentary behavior, opportunities for physical activity, and increased use of labor-saving devices should be taken into account (16-19) as well as transportation and land use policies, zoning regulations, and even political philosophies (20). It is possible to speculate that the "Mediterranean dietary style" (21), together with the absence of a systematic increase in portion size (22), may have been important factors that contributed to counteract epidemic of obesity in Italy. In fact adherence to the Mediterranean diet is associated with lower prevalence of obesity (23). Furthermore, the increased skewness in BMI distribution observed both in Italy and in the United States could suggest that environmental factors have a stronger effect on the upper portion of the distribution; there may be a subgroup of the population that is more susceptible to these influences suggesting a gene-environment interaction effect (16).

Among the strengths of this study there are the large sample size (representative of the general adult Italian population) and the high response rate (thus, selection bias is unlikely to be present). Our findings also complement and expand previous reports $(14,15,24)$.

Some limitations should be recognized. It has been shown that self-reported weight and height data underestimate the prevalence of overweight and obesity (25-27), which can be dependent by several factors $(27,28)$. However, when nationwide proportions of overweight and obesity are of interest, self-reported measurements of weight and height have been in general accepted $(4,29)$, and compared with telephone surveys, household face-to-face interviews produced more accurate results (30). Actually, it is unlikely that the lower prevalence of overweight and obesity observed in our study compared with that of the United States may be totally attributable to underreporting. More importantly, even if self-reported height and weight data may contain considerable errors, perhaps they could be considered adequate at least for tracking trends because of the consistency in the sample design of the MHSs; it is unlikely that errors in self-reported height and weight would flatten trends in a 25- year period in the presence of a rising obesity epidemic.

In conclusion, in Italy, data from surveys representative of the general adult population show that moderate trends in overweight outcome are present, more evident in men than in women. More than $50 \%$ of Italian adult men and about 1 of 3 women are overweight or obese. Obesity epidemic is one of the major issues in the United States and other developed countries with significant health and economic implications. However, if by "epidemic" we mean that in Italy obesity is steadily increasing, then our results give little support to this interpretation. In fact, trends observed in a 25-year period suggest that the rates of changes in the prevalence of overweight and/or obesity are not increasing.

\section{REFERENCES}

1. Bray GA. Health hazards of obesity. Endocrinol Metab Clin North Am. 1996;25:907-919.

2. Flegal KM, Graubard BI, Williamson DF, Gail MH. Excess deaths associated with underweight, overweight, and obesity. JAMA. 2005;293: 1861-1867.

3. Fontaine KR, Redden DT, Wang C, Westfall AO, Allison DB. Years of life lost due to obesity. JAMA. 2003;289:187-193.

4. Mokdad AH, Bowman BA, Ford ES, Vinicor F, Marks JS, Koplan JP. The continuing epidemics of obesity and diabetes in the United States. JAMA. 2001;286:1195-1200.

5. Flegal KM, Carrol MD, Ogden CL. Prevalence and trends in obesity among US adults, 1999-2000. JAMA. 2002;288:1723-1727.

6. Ogden CL, Carrol MD, Curtin LR, McDowell MA, Tabak CJ, Flegal KM. Prevalence of overweight and obesity in the United States, 1999-2004. JAMA. 2006;295:1549-1555.

7. Prentice AM. The emerging epidemic of obesity in developing countries. Int J Epidemiol. 2006;35:93-99.

8. Seidell JC. Prevalence and time trends of obesity in Europe. J Endocrinol Invest. 2002;26:816-822.

9. ISTAT. Manuale di Tecniche di Indagine. ISTAT, Collana Metodi e Norme. Volume 1-6 (in Italian). Rome: ISTAT; 1989.

10. Fraboni R, Rosina A, Orsini S, Baldazzi B. A micro analysis of the macro differences in refusal risk among metropolitan areas. The case of the Italian multipurpose survey. Stat Methods Appl. 2005;14:283-295.

11. Levy PS, Lemeshow S. Sampling of Populations: Methods and Applications. 3rd ed. New York: John Wiley and Sons; 1999.

12. Chambers JM, Cleveland WS, Kleiner B, Tukey PA. Graphical Methods of Data Analysis. (The Wadsworth Statistics/Probability Series). Boston, MA: Duxbury Press; 1983 48-57.

13. R Development Core Team. R: A language and environment for statistical computing. R Foundation for Statistical Computing, Vienna, Austria, 2007. Available at: http://www.R-project.org. Accessed January 15, 2010. 
14. Pagano R, La Vecchia C, Decarli A, Negri E, Franceschi S. Trends in overweight and obesity among Italian adults, 1983 through 1994. Am J Public Health. 1997;87:1869-1870.

15. Calza S, Decarli A, Ferraroni M. Obesity and prevalence of chronic diseases in the 1999-2000 Italian National Health Survey. BMC Public Health. 2008;8:140.

16. Flegal KM, Troiano RP. Changes in the distribution of body mass index of adults and children in the US population. Int J Obes. 2000;24:807-818.

17. Schroder H, Marrugat J, Vila J, Covas MI, Elosua R. Adherence to the traditional Mediterranean diet is inversely associated with body mass index and obesity in a Spanish population. J Nutr. 2004;134:3355-3361.

18. Popkin BM. Using research on the obesity pandemic as a guide to a unified vision of nutrition. Public Health Nutr. 2005;8:724-729.

19. Nielsen SJ, Popkin BM. Patterns and trends in food portion sizes, 19771998. JAMA. 2003;289:450-453.

20. Kushi LH. Epidemiologic research on the obesity epidemic. A socioenvironmental perspective. Epidemiology. 2006;17:131-132.

21. Trichopoulou A, Naska A, Orfanos P, Trichopoulos D. Mediterranean diet in relation to body mass index and waist-to-hip ratio: The Greek European Prospective Investigation into Cancer and Nutrition Study. Am J Clin Nutr. 2005;82:935-940.

22. Silventoinen K, Sans S, Tolonen H, Monterde D, Kuulasmaa K, Kesteloot $\mathrm{H}$, et al. WHO MONICA Project. Trends in obesity and energy supply in the WHO MONICA Project. Int J Obes Relat Metab Disord. 2004:28:710-718.
23. Buckland G, Bach A, Serra-Majem L. Obesity and Mediterranean diet: A systematic review of observational and intervention studies. Obes Rev. 2008;9:582-593.

24. Gallus S, Colombo P, Scarpino V, Zuccaro P, Negri E, Apolone G, et al. Overweight and obesity in Italian adults 2004, and an overview of trends since 1983. Eur J Clin Nutr. 2006;60:1174-1179.

25. Rowland ML. Self-reported weight and height. Am J Clin Nutr. 1990;52:1125-1133.

26. Kuskowska-Wolk A, Karlsson P, Stolt M, Rössner S. The predictive validity of body mass index based on self-reported weight and height. Int J Obes. 1989;13:441-453.

27. Yun S, Zhu B-P, Black W, Brownson RC. A comparison of national estimates of obesity prevalence from the behavioural risk factor surveillance system and the national health and nutrition examination survey. Int J Obes. 2006;30:164-170.

28. John U, Hanke M, Grothues J, Thyrian JR. Validity of overweight and obesity in a nation based on self-report versus measurement device data. Eur J Clin Nutr. 2006;60:372-377.

29. Mokdad AH, Ford ES, Bowman BA, Dietz WH, Vinicor F, Bales VS, et al Prevalence of obesity, diabetes and obesity-related health risk factors, 2001. JAMA. 2003;289:76-79.

30. Nelson DE, Powell-Griner E, Machell T, Kovar MG. A comparison of national estimates from the National Health Interview Survey and the Behavior Risk Factor Surveillance System. Am J Public Health. 2003;93:1335-1341. 